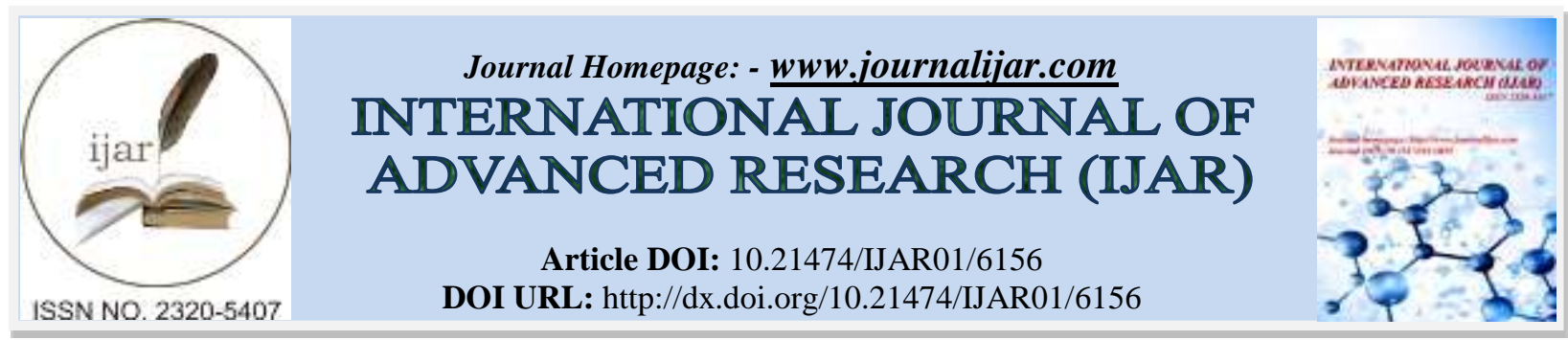

RESEARCH ARTICLE

\title{
STUDY OF BREAST FEEDING PRACTICES AMONG WORKING AND NON WORKING WOMEN ATTENDING A MATERNITY CARE HOSPITAL, THIRUVALLUR DISTRICT, TAMILNADU, INDIA.
}

Thenisha. A.

\section{Manuscript Info}

\section{Manuscript History}

Received: 24 October 2017

Final Accepted: 26 November 2017

Published: December 2017

\section{Keywords:-}

Pre lacteal feeds, Colostrum, Formula milk.

\begin{abstract}
The breast milk is the best milk for the baby. In this fast growing world, the burden of employment of working women during their breast feeding period greatly affects their breast feeding practices. So in order to study the breast feeding practices of both working and non working women ,a cross sectional study among working and Non working breastfeeding practices was attempted .

Methods: This was the institutional based study carried out in Vijaya Hospital, a maternity care hospital at Thiruvallur District. A convenient sampling was carried out. Among the total sample size of 172, 60 were working mothers and 112 were non working mothers . A structured questionnaire was given to them and the data obtained was subjected to the analysis The results were given as descriptive statistics and a Proportionality test was carried out.

Results: Nearly $65 \%$ of working women practices pre lacteal feed and $70 \%$ of working women practices formula milk. Nearly $41.7 \%$ of working women had experienced breast pain which may due to delay in breast feeding depending on their burden of work. Nearly $51.7 \%$ of infants of working women had cough, $35 \%$ of infants had cold, $11.7 \%$ of infants had fever respectively. After performing Proportionality tests, the results are the practices among working and non working women relating to pre lacteal feeds, colostrum and formula milk are not same.

Conclusion: Therefore this study has brought out the breast feeding practices among working and Non working women which is mainly due to the burden of work that working women and its impact over the health of their infants. The increased burden of employment is the main reason of the difference in the breast feeding practices among working and Non working women. This study has brought into light and educate the mothers about the benefits of breast feeding for baby.
\end{abstract}

Copy Right, IJAR, 2017,. All rights reserved.

\section{Introduction:-}

Increasing trends among working mothers getting back to work after brief maternity leave interferes with breastfeed needs of the baby. The compromised breast feeding practices leads to deterioration in child's health.

Globally, Fewer than 35\% of infants are exclusively breastfed during the first 4 months of life. At National level, according to the study "Infant and young child feeding behaviors among working mothers in India" ,Ryan and co

Corresponding Author:- Thenisha . A. 
researches demonstrated that breast feeding rates in the immediate post delivery period among part time and full time working women were closer at $68.8 \%$ and $65.5 \%$ respectively. Studies on women from different parts of India substantiate widespread prevalence of suboptimal practices. A study from Northern India reported that breastfeeding within one hour and exclusive breastfeeding for six months was practiced by only $19 \%$ and 5\% women respectively. As a consequence of sub optimal feeding behavior among mothers, India is struggling to achieve the targeted reduction in the Under five Mortality rate by two thirds between 1990and 2015.Being the capital city of India, New Delhi is home to working women from all parts of country. In India,129.1 million strong group of working women comprises one of the most prominent and expanding community of mothers. At State level, in Tamil Nadu Prevalence of exclusive breast feeding is $69.35 \%$ up to six months of age.

Breast feeding is the fundamental aspect of child rearing that a women copes with. It creates a wonderful relationship between mothers and their babies. The importance of breast feeding to child health is highlighted by the yearly World Breast feeding week. Work emerges as a major challenge to optimal breast feeding for mothers. Low income mothers are presented with unique challenges as most of them are pretty traders or casual laborers. In most cases, they are not offered the maternity leave also. Further, missing work puts them at the risk of losing their jobs. Moreover, carrying children to work is not an option for most of them, as their working conditions do not allow them to do so. As a result, some mothers forego exclusive or any breastfeeding to save their jobs as have to feed their families. Therefore it is important to understand the breast feeding practices and the challenges faced by them. And also the interruption in breast feeding practices leads to deterioration in child health outcome.

The study was carried out at rural and semi urban area in which there are large number of working women. This research has brought out the challenges faced by the lactating working mothers and also determine their child health outcomes. This study has also created awareness among the working and Non working lactating mothers about the significance of breastfeeding.

\section{Need Of The Study:-}

The need of the study was to assess the factors affecting the breast feeding practices among working women and Non working women and their impact on child health.

Numerous studies have revealed that one of the barriers to breast feeding is the work status. With enlarged urbanization and industrialization, more and more women have joined the workforce. An estimated 50\% of women employed in the workforce are of reproductive age and return to work within one year of infants. Increased female literacy rate to $65.46 \%$ according to 2011 census and rapid urbanization has increased workforce participation rate of females in rural sector to $26.1 \%$ and $13.8 \%$ in urban sector.

A Woman's ability to breastfeed is markedly reduced when she returns to work if breastfeeding breaks are not available, if quality infant care near her workplace is inaccessible or unaffordable and if no facilities are available for storing breast milk.

Keeping in mind women's empowerment increased women workforce in India, this study was conducted with the objective of assessing breastfeeding practices among working and non working women.

\section{Objectives:-}

1. To compare the breast feeding practices among working and Non-Working lactating mothers

2. To study the impact of Breast feeding practices on Infants health

\section{Literature Review:-}

Prevalence of Exclusive Breast feeding practices among Rural women in Tamil Nadu:-

Poor Infant feeding practices and their effective consequences are one of the major problems of the world and a serious obstacle to social and economic development. In this study, among children who were exclusively breastfed, $62.6 \%$ did not have any episode of illness, only $26.2 \%$ had one to three episodes of illness and $11.1 \%$ had more than three episodes. This shows exclusive breast feeding is protective to the baby as it helps to combat diseases by increasing the immune status of the child. The reasons for bottle feeding is that inadequate breast milk secretion. Other reasons were poor weight gain and some thought that bottle fed is more nutritious than breastfeeding. 
Breast Feeding Practices and Newborn Care in Rural Areas: A Descriptive Cross-Sectional Study:-

This study was aimed to describe the breastfeeding practices prevalent in rural areas and the primary objective was to describe the breastfeeding and newborn care practices in rural areas and to study the factors affecting the initiation and duration of breastfeeding. The study was conducted in Primary Health Centre that is attached to a medical college at Rural Bangalore, Karnataka. The results of the study was $97 \%$ mothers initiated breastfeeding, $19 \%$ used Pre lacteal feeds.

Impact of feeding and breastfeeding practices on the nutritional status of infants in a district of Andhra Pradesh, India.:-

This was a Cross sectional household study to assess the feeding practices of Infants and young children in rural areas of Andhra Pradesh. In this study, age specific feeding patterns were classified using frequencies, proportions and survival analysis. Logistic regression was done with feeding practice as dependent and socio demographic factors as independent variables. Early initiation of breast feeding practices were associated with community, type of family and education of mothers.

Breastfeeding practices in villages of central Karnataka: -

Breast feeding practices in villages of central Karnataka was a community based study and a stratified sampling method is used. The results were exclusive breast feeding was at $94 \%$ at one month, $83.5 \%$ at two months, $72.5 \%$ at three months. Among infants younger than one year,49.4\% were bottle fed. The major reasons for introducing bottle feeding is no enough breast milk, subsequent pregnancy and ill health of mother. These findings show that rural mothers in central Karnataka delay initiation of breast feeding, reject the colostrum and use pre lacteal feeds.

Breast feeding practices, Demographic variables and their association with Morbidities in Children.:This was also a cross sectional Based study of mothers of children aged less than five years of age. The study was conducted among 781 mothers. Multi variable logistic regression was used and it showed that initiation of breast feeding with in a hour of birth was 57.5\%,55.9\% gave exclusive breastfeeding for six months,89\% stopped breastfeeding before two years of age. Starting breastfeeding after an hour of birth, severe malnutrition and breast feeding for lesser than two years increased rates of Diarrhea.

Study of breast feeding practices amongst Post natal mothers in urban slum areas in Sholapur, Maharashtra:-

This was a cross sectional observational study and was carried out over the period of January 2012 to December 2012.The objective of the study was to know the various breastfeeding practices and knowledge in lactating post natal mothers. The results were out of total, $14 \%$ mothers received advice on breastfeeding during Anti natal care, $6 \%$ initiated breastfeeding within one hour, $37 \%$ mothers had given prelacteals., $22 \%$ mothers discarded colostrum,55\% babies received demand feeding. In conclusion, very few mothers initiated breastfeeding at correct time. Wrong customs like giving pre lacteals and discarding colostrum is still practiced in the society.

\section{Operational definitions:-}

Working mother: Those who earn income from outside home includes all sectors of employment from labors to professionals.

Non working mothers:-

Those who stay in home and do not go outside for income.

Methodology:-

Study Design:-

This was a cross sectional study to be conducted among Working and Non Working lactating mothers in Thiruvallur district.

Study Area:-

Vijaya Hospital. Thiruvallur District, institutional based study.

Sampling:-

A Convenient sampling will be carried out. 


\section{Sample Size:-}

The sample size of 172 breastfeeding mothers were studied during the study period.

\section{Sample Selection:-}

Mothers with their babies wo came for check up at the hospital was registered and a structured questionnaire was given for them with the questions relating to Breastfeeding practices, Duration and type of illness of infants, Maternity leave and availability of child care centers.

Inclusion Criteria:-

All Working and Non Working mothers who were willing to participate in the study .

Exclusion Criteria:-

Low birth weight babies, Twins babies, Babies with congenital anomalies will be excluded.

Tool:-

A structured questionnaire was given to the study participants and followed by data collection.

\section{Data collection:-}

It took nearly twenty to twenty five days for completing the data collection. Data collection was carried out in the Month of June 2017 respectively.

\section{Data entry:-}

The data was entered in the SPSS software and was followed by Data cleaning and Data management. The data was analyzed and output was generated using SPSS software and the results was interpreted.

\section{Statistical analysis:-}

Descriptive statistics and proportionality test was carried out for comparing the two groups of lactating mothers.

\section{Ethical consideration:-}

The Research Proposal was submitted to the Institutional Review Board of School of Public Health, SRM University.

\section{Results:-}

Total number of participants studied -172

Working mothers-60

Non working mothers-112

\section{Distribution Of Study Subjects Based On Their Breast Feeding Practices:-}

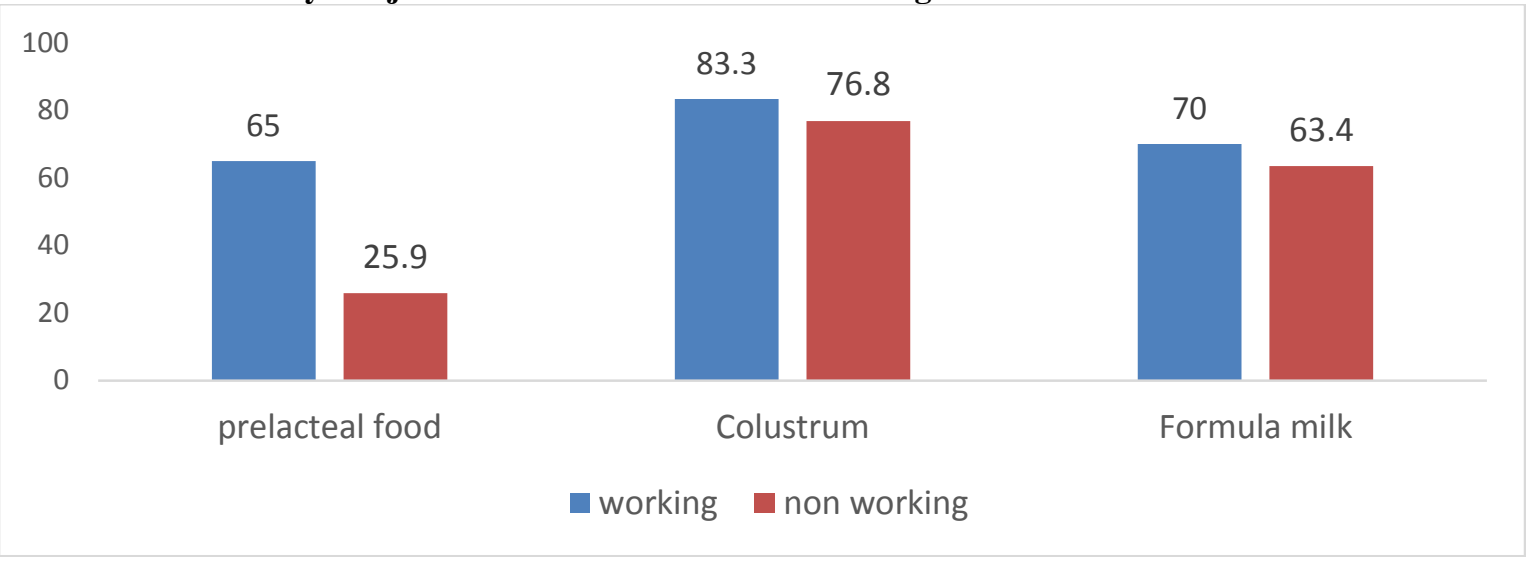



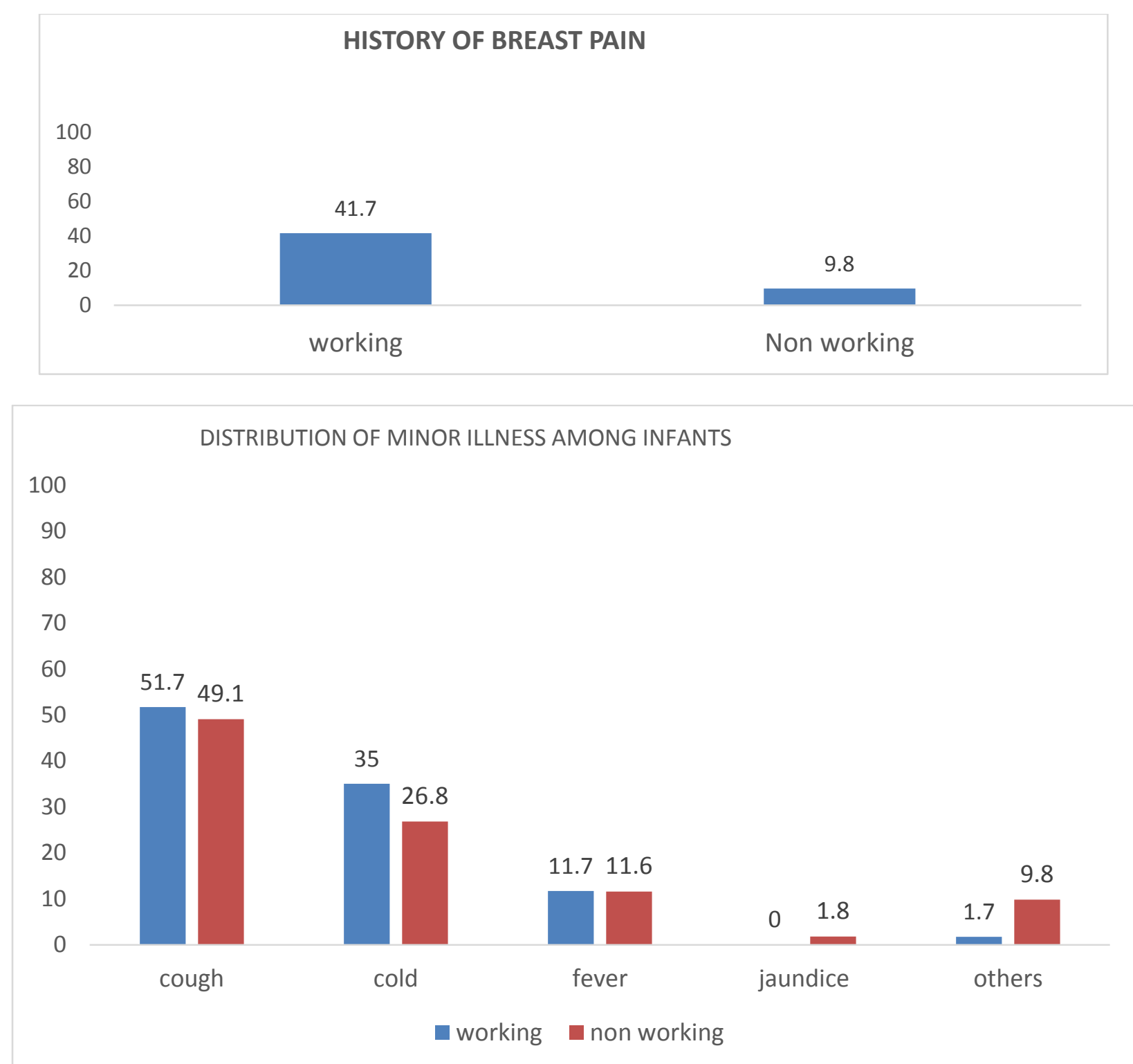

After performing Proportionality tests, the results are the practices among working and non working women relating to pre lacteal feeds ,colostrum and formula milk are not same.

\section{Limitations:-}

The Study did not analyze about the type of delivery of mothers which has the major influence over the breast feeding practices. The study period was also limited.

\section{Conclusion:-}

In this study, the results obtained were given through bar diagrams . Nearly $65 \%$ of working women practices pre lacteal feed and $70 \%$ of working women practices formula milk. Nearly $41.7 \%$ of working women had experienced breast pain which may due to delay in breast feeding depending on their burden of work. Nearly $51.7 \%$ of infants of working women had cough, $35 \%$ of infants had cold, $11.7 \%$ of infants had fever respectively. Therefore this study has brought out the breast feeding practices among working and Non working women which is mainly due to the burden of work that working women faces and its impact over the health of their infants. 


\section{References:-}

1. An assessment of Breast feeding practices and infant feeding pattern among mothers In Mauritius Journal of Nutrition and metabolism.

2. Impact of feeding and breast feeding practices on the nutritional status of infants in the district of Andhra Pradesh, India.

1. National Institute of Nutrition. ,Hyderabad., Indian council of Medical Research, source : PUBMED.

3. Breast feeding practices in villages of central Karnataka .CR.1996 PUBMED

4. Breast feeding practices, Demographic variables and their association with morbidities in children ,central research services, Gujarat, India. Patel .GV., PUBMED

5. Study of Breast feeding practices among working women attending a tertiary care hospital, Mysore ,Karnataka ,India. Prakash med 2016 Breast feeding practices of Urban slums of western India. International journal of interdisciplinary and multidisciplinary studies.

6. Study of Breast feeding practices among PNC mothers in urban slum area in Sholapur city, Maharashtra. Scholars journal of Applied medical sciences. 